RESEARCH REPORT

\title{
Socioeconomic inequalities in mortality among elderly people in 11 European populations
}

\author{
M Huisman, A E Kunst, O Andersen, M Bopp, J-K Borgan, C Borrell, G Costa, P Deboosere, \\ G Desplanques, A Donkin, S Gadeyne, C Minder, E Regidor, T Spadea, T Valkonen, \\ J P Mackenbach
}

J Epidemiol Community Health 2004;58:468-475. doi: 10.1136/jech.2003.010496

See end of article for authors' affiliations

Correspondence to: Dr M Huisman

Department of 'Public Health, Erasmus MC University Medical Center Rotterdam, PO Box 1738, 3000 DR Rotterdam, Netherlands; m.huisman@ erasmusmc.n

Accepted for publication 26 September 2003
Study objective: To describe mortality inequalities related to education and housing tenure in 11 European populations and to describe the age pattern of relative and absolute socioeconomic inequalities in mortality in the elderly European population.

Design and Methods: Data from mortality registries linked with population census data of 11 countries and regions of Europe were acquired for the beginning of the 1990s. Indicators of socioeconomic status were educational level and housing tenure. The study determined mortality rate ratios, relative indices of inequality (RII), and mortality rate differences. The age range was 30 to $90+$ years. Analyses were performed on the pooled European data, including all populations, and on the data of populations separately. Data were included from Finland, Norway, Denmark, England and Wales, Belgium, France, Austria, Switzerland, Barcelona, Madrid, and Turin.

Main results: In Europe (populations pooled) relative inequalities in mortality decreased with increasing age, but persisted. Absolute educational mortality differences increased until the ages $90+$. In some of the populations, relative inequalities among older women were as large as those among middle aged women. The decline of relative educational inequalities was largest in Norway (men and women) and Austria (men). Relative educational inequalities did not decrease, or hardly decreased with age in England and Wales (men), Belgium, Switzerland, Austria, and Turin (women).

Conclusions: Socioeconomic inequalities in mortality among older men and women were found to persist in each country, sometimes of similar magnitude as those among the middle aged. Mortality inequalities among older populations are an important public health problem in Europe.
$\mathrm{S}$ ocioeconomic mortality inequalities among older ages have been less discussed as inequalities among younger age groups. However, literature on the topic is increasing and it seems that more researchers developed an interest in mortality inequalities related to socioeconomic status in elderly populations. The lion's share of mortality occurs at old age and any amount of inequality in mortality points to an important source of potential to improve health in the population.

It has been consistently found that among adult populations, mortality at the lower end of the socioeconomic scale is higher than mortality at the higher end. ${ }^{1-4}$ Also among elderly populations, socioeconomic mortality inequalities are found..$^{5-13}$ These inequalities often decrease with increasing age. ${ }^{10}{ }^{14-16}$ However, there are important reasons to determine socioeconomic inequalities among elderly populations.

One reason is that most of what is known of socioeconomic inequalities in mortality among the elderly population stems from research in northern European countries. The question remains as to whether the results from these studies are generalisable to other parts of Europe.

A second reason is that the use of every socioeconomic indicator has its own specific problems when applied to elderly populations. ${ }^{10}$ Education is considered to be an appropriate indicator of socioeconomic status by some, ${ }^{8}$ but the concept of socioeconomic status is broader than education alone. There may yet be other indicators beside the traditional ones (occupation, income, and education) that are more adequate measures of socioeconomic status for elderly populations. Housing tenure for instance is an indicator that is often used in research from the UK. ${ }^{6}{ }^{17-19}$ Housing tenure as an indicator of socioeconomic status may show substantial mortality inequalities in other countries as well.
Thirdly, when comparing the reported inequalities among the elderly age group with inequalities among the middle aged in relative terms alone, the situation in absolute terms is overlooked. Relative inequalities may decrease with age, but absolute differences may not. Absolute differences are important as well, as they refer to the absolute numbers of avoidable deaths. In aging populations, the number of avoidable deaths can exceed thousands even when relative inequalities can hardly be demonstrated.

This study aims to describe the age pattern of not only relative, but also absolute, mortality inequalities related to both level of education and housing tenure in Europe, using population data. Elderly populations are compared with middle aged populations. To determine the generalisability of results that are found in one part to other parts of Europe, the study includes data from northern as well as central and southern parts of Europe.

\section{METHODS}

Population data from national, regional, and urban longitudinal mortality studies were used. We used data on mortality from vital registries linked with data from population censuses. From these census linked mortality data we acquired the number of deaths and the number of person years at risk, by sex, five year age group (age specified at the start of the follow up; with 30-34 as the youngest age group and $90+$ as the oldest group), level of education and housing tenure (the second not present in all studies). These two measures of socioeconomic status were validated for the population as part of the population census. The population censuses were carried out by national, regional, and urban statistical bureaus. Table 1 lists the countries and cities that 
Table 1 Follow up periods of the included populations and the number of person years at risk (ages $30+$ years)

\begin{tabular}{llll}
\hline & & \multicolumn{2}{l}{ Number of person years at risk } \\
\cline { 3 - 4 } Country/Region & Follow up period & Men & Women \\
\hline Finland & $1991-1995$ & 6758254 & 7690004 \\
Norway & $1990-1995$ & 5592620 & 6031051 \\
Denmark & $1991-1995$ & 7035378 & 7677538 \\
England/Wales & $1991-1996$ & 796618 & 894517 \\
Belgium & $1991-1995$ & 13047398 & 14587998 \\
France & $1990-1994$ & 1432641 & 1192537 \\
Switzerland* & $1991-1995$ & 5673634 & 6747784 \\
Austria & $1991-1992$ & 2092646 & 2459625 \\
Turin (city of) & $1991-1996$ & 1276242 & 1532675 \\
Barcelona (city of) & $1992-1996$ & 2263963 & 2798811 \\
Madrid (region of) & $1996-1997$ & 2047072 & 2398763 \\
\hline *Swiss nationals living in the predominantly German speaking cantons. & \\
\hline
\end{tabular}

are included in the study. Most studies covered the entire national, regional, or urban population. The data for England/ Wales, Norway, and France were representative samples of the national populations. Swiss data were representative of the population in the predominantly German speaking cantons.

The level of education was initially classified according to national categories of education. We reclassified these into three levels of education $(1=$ low, 2 = middle, $3=$ high $)$, approximately corresponding with the following levels of the International Standard Classification of Education (ISCED): 0-2 (pre-primary, primary, and lower secondary education), 3 (upper secondary education), and 4-6 (post-secondary education). ${ }^{20}$ Percentage of missing information for education was large in Denmark (10\%) but below $4 \%$ in all other populations. Table 2 gives the resulting population distribution of the three levels of this classification. For Switzerland applying the general classification proved difficult, as is apparent from the deviating distribution over the population. Educational data were not available for Denmark and France for ages older than 60-69 years and 70-79 years respectively.

Housing tenure was divided into the following three categories: owner occupiers, tenants, and institutionalised populations. Table 3 gives the distribution of the population according to housing tenure. Tenants were specified as representing lower socioeconomic status and owner occupiers as higher status. The institutionalised were left out of analysis. Tenure data were not available for France for those older than 79 years.

We determined age standardised mortality rates by sex, 10 year age group, and education/housing tenure. The rates were standardised by five year age groups by means of the direct method, with the population of the EU plus Norway of 1995 as the standard. ${ }^{21}$ Absolute socioeconomic differences were expressed as rate differences. These are the differences between the mortality rates of the groups with a lower socioeconomic status (= level 1 of the general educational classification/tenants) with the mortality rates of the groups with a higher status (levels 2 and 3 of the general educational classification/owner occupiers). For Switzerland we combined levels 1 and 2 of the general educational variable instead of levels 2 and 3 to compare about equally large groups for this country as for the other countries in the study.

With Poisson regression analyses we calculated two indicators of relative mortality inequalities, rate ratios, and the relative index of inequality (RII). The rate ratios were controlled for age, and country in the case of analyses of

Table 2 Distribution of the educational variable, middle aged (50-59 years) and elderly (80-89 years) men and women

\begin{tabular}{|c|c|c|c|c|c|c|c|}
\hline \multirow[b]{2}{*}{ Country/City } & \multirow[b]{2}{*}{ Age } & \multicolumn{3}{|c|}{ Percentage of the male population } & \multicolumn{3}{|c|}{ Percentage of the female population } \\
\hline & & Low & Middle & High & Low & Middle & High \\
\hline \multirow[t]{2}{*}{ Finland } & $50-59$ & 62.3 & 27.0 & 10.7 & 63.4 & 27.9 & 8.7 \\
\hline & $80-89$ & 82.2 & 11.1 & 6.6 & 86.6 & 9.1 & 4.3 \\
\hline \multirow[t]{2}{*}{ Norway } & $50-59$ & 80.7 & 9.2 & 10.1 & 87.3 & 8.1 & 4.6 \\
\hline & $80-89$ & 90.6 & 4.0 & 5.4 & 95.2 & 4.2 & 0.6 \\
\hline \multirow[t]{2}{*}{ Denmark } & $50-59$ & 70.0 & 16.0 & 14.0 & 71.0 & 19.0 & 10.0 \\
\hline & $60-69$ & 74.3 & 14.4 & 11.3 & 77.1 & 15.8 & 7.2 \\
\hline \multirow[t]{2}{*}{ England/Wales } & $50-59$ & 79.4 & 11.6 & 9.0 & 85.9 & 11.1 & 3.0 \\
\hline & $80-89$ & 89.0 & 5.4 & 5.7 & 93.3 & 5.3 & 1.3 \\
\hline \multirow[t]{2}{*}{ Belgium } & $50-59$ & 71.9 & 16.1 & 11.9 & 77.2 & 14.0 & 8.8 \\
\hline & $80-89$ & 87.7 & 6.2 & 6.2 & 93.1 & 3.9 & 3.0 \\
\hline \multirow[t]{2}{*}{ France } & $50-59$ & 80.1 & 8.1 & 11.8 & 81.9 & 10.0 & 8.1 \\
\hline & $70-79$ & 80.4 & 8.8 & 10.8 & 83.1 & 9.2 & 7.7 \\
\hline \multirow[t]{2}{*}{ Switzerland } & $50-59$ & 18.2 & 58.8 & 23.0 & 42.5 & 52.3 & 5.2 \\
\hline & $80-89$ & 38.5 & 49.2 & 12.3 & 68.8 & 29.2 & 2.0 \\
\hline \multirow[t]{2}{*}{ Austria } & $50-59$ & 79.9 & 10.8 & 9.3 & 79.0 & 16.6 & 4.4 \\
\hline & $80-89$ & 80.2 & 10.5 & 9.4 & 88.2 & 9.8 & 2.1 \\
\hline \multirow[t]{2}{*}{ Turin } & $50-59$ & 75.5 & 16.8 & 7.7 & 84.8 & 11.6 & 3.6 \\
\hline & $80-89$ & 83.2 & 8.8 & 8.0 & 92.2 & 6.5 & 1.3 \\
\hline \multirow[t]{2}{*}{ Barcelona } & $50-59$ & 72.2 & 11.6 & 16.2 & 81.6 & 7.4 & 8.7 \\
\hline & $80-89$ & 80.0 & 8.0 & 12.1 & 90.2 & 2.5 & 3.9 \\
\hline \multirow[t]{2}{*}{ Madrid } & $50-59$ & 67.6 & 14.1 & 18.3 & 81.1 & 9.6 & 9.3 \\
\hline & $80-89$ & 81.8 & 6.9 & 11.4 & 93.0 & 3.5 & 3.4 \\
\hline \multirow[t]{2}{*}{ All countries* } & $50-59$ & 67.4 & 19.7 & 13.0 & 74.1 & 19.0 & 6.9 \\
\hline & $80-89$ & 78.4 & 13.2 & 8.4 & 88.6 & 8.8 & 2.6 \\
\hline
\end{tabular}


Table 3 Distribution of the housing tenure variable, middle aged (50-59 years) and elderly (80-89 years) men and women

\begin{tabular}{|c|c|c|c|c|c|c|c|}
\hline \multirow[b]{2}{*}{ Country/City } & \multirow[b]{2}{*}{ Age } & \multicolumn{3}{|c|}{ Percentage of the male population } & \multicolumn{3}{|c|}{ Percentage of the female population } \\
\hline & & Tenants & Owners & In an institution & Tenants & Owners & In an institution \\
\hline \multirow[t]{2}{*}{ Finland } & $50-59$ & 13.7 & 83.6 & 0.5 & 13.9 & 84.2 & 0.3 \\
\hline & $80-89$ & 13.6 & 74.3 & 7.2 & 22.6 & 60.8 & 11.7 \\
\hline \multirow[t]{2}{*}{ Norway } & $50-59$ & 12.2 & 87.7 & 0.1 & 10.9 & 89.1 & 0.1 \\
\hline & $80-89$ & 71.9 & 25.6 & 2.5 & 32.6 & 63.7 & 3.7 \\
\hline \multirow[t]{2}{*}{ Denmark } & $50-59$ & 26.3 & 71.8 & 0.5 & 31.3 & 67.4 & 0.3 \\
\hline & $80-89$ & 40.7 & 47.6 & 8.5 & 30.2 & 52.9 & 13.3 \\
\hline \multirow[t]{2}{*}{ England/Wales } & $50-59$ & 16.6 & 67.8 & 0.5 & 18.3 & 68.1 & 0.5 \\
\hline & $80-89$ & 29.5 & 51.3 & 7.5 & 32.7 & 42.5 & 13.1 \\
\hline \multirow[t]{2}{*}{ Belgium } & $50-59$ & 21.3 & 73.8 & 0.4 & 21.4 & 74.1 & 0.4 \\
\hline & $80-89$ & 23.7 & 63.3 & 7.4 & 26.6 & 51.9 & 14.4 \\
\hline \multirow[t]{2}{*}{ France } & $50-59$ & 42.2 & 57.8 & NA & 39.7 & 60.3 & NA \\
\hline & $70-79$ & 36.3 & 63.7 & NA & 37.0 & 63.0 & NA \\
\hline \multirow[t]{2}{*}{ Turin } & $50-59$ & 36.9 & 59.4 & 0.4 & 35.6 & 60.4 & 1.0 \\
\hline & $80-89$ & 33.2 & 57.4 & 2.5 & 38.3 & 47.1 & 6.0 \\
\hline \multirow[t]{2}{*}{ All countries* } & $50-59$ & 29.2 & 67.4 & 0.4 & 28.2 & 68.9 & 0.4 \\
\hline & $80-89$ & 28.5 & 60.8 & 6.6 & 28.2 & 55.0 & 11.7 \\
\hline
\end{tabular}

pooled data. The combined middle and high educational categories (for Switzerland only the high educational category), and the house owners were specified as the reference groups. The RII was determined for level of education to control for the distribution of the population over the levels of education. This regression based index contrasts the rate of mortality that is predicted for the lower end of the educational hierarchy with the rate of mortality at the higher end of the hierarchy into a ratio. ${ }^{22}$ The use of the RII allows for a direct comparison of relative inequalities between countries. We used the SAS statistical package, version 6.12 to determine these relative measures. ${ }^{23}$

We created two pooled European datasets with country specific weights assigned to the individual observations, so that the separate populations carried equal weight in the results of the European analyses. One set included all countries, with the exception of Denmark and France for which no information on education among elderly populations could be given. The other dataset included all countries for which information was available on housing tenure, with the exception of France. The analyses for educational inequalities in Europe were performed on the first pooled dataset, and analyses for inequalities related to housing tenure were performed on the second dataset.

The rate ratios, RIIs, and rate differences were determined for the separate countries and cities for the age groups 50-59 (middle aged), 60-69, 70-79, and 80-89 (elderly populations),

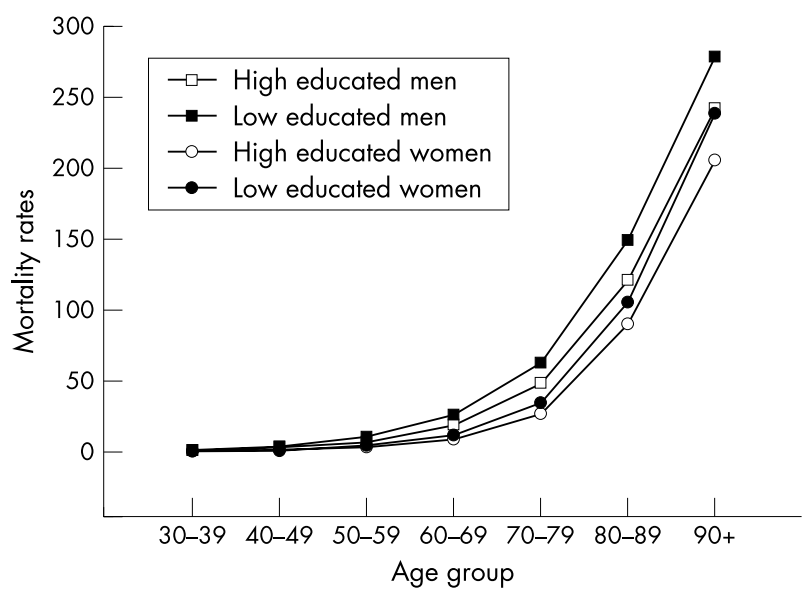

Figure 1 Age pattern of mortality rates for Europe, men and women, related to education and for the pooled data for all age groups of 10 years, ranging from ages 30-39 to 90+. The studies of Barcelona and Madrid were taken together in the analyses of separate countries to represent Spain. A former study showed that the size of inequalities in mortality in both cities were similar. ${ }^{24}$

\section{RESULTS}

Mortality rates for European men and women for the age groups 30-39 to $90+$ are plotted in figures 1 and 2. For education, the mortality rates among high and low status groups increasingly diverged with older age (fig 1). The rates for men and women showed a similar pattern. The rates for housing tenure initially showed a similar pattern as those of education-that is, divergence with increasing age (fig 2). At the oldest ages, however, the rates for tenure converged. The rates of female tenants were smaller than those of female owner occupiers after age 80 .

Table 4 shows rate ratios and rate differences per age group. Relative inequalities (rate ratios) decreased gradually with age, with the exception of educational inequalities among women. These were stable from ages 40-49 to 70-79. Educational inequalities among men and women persisted until the oldest ages, but inequalities related to tenure did not. Absolute educational differences increased consistently with increasing age among both sexes and were largest for the age group 90+. Absolute differences by tenure initially also increased with age, but decreased among the oldest old.

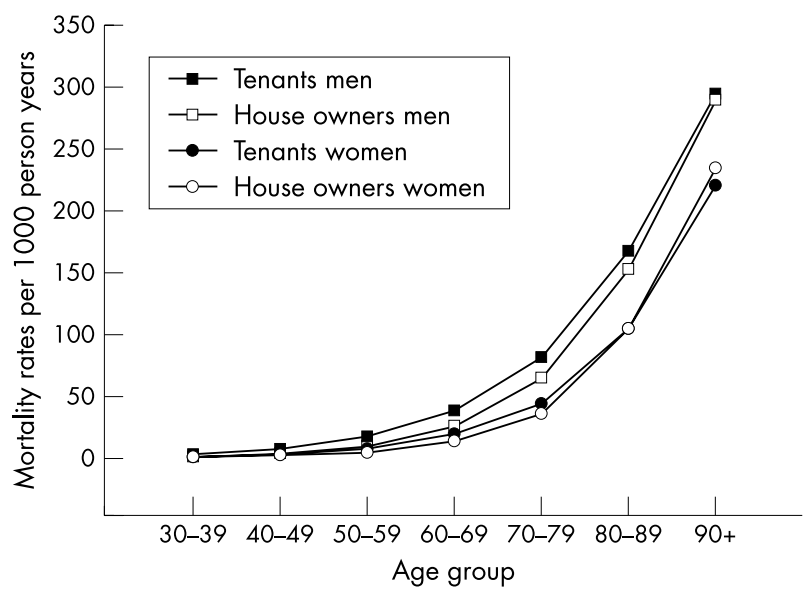

Figure 2 Age pattern of mortality rates for Europe, men and women, related to housing tenure 


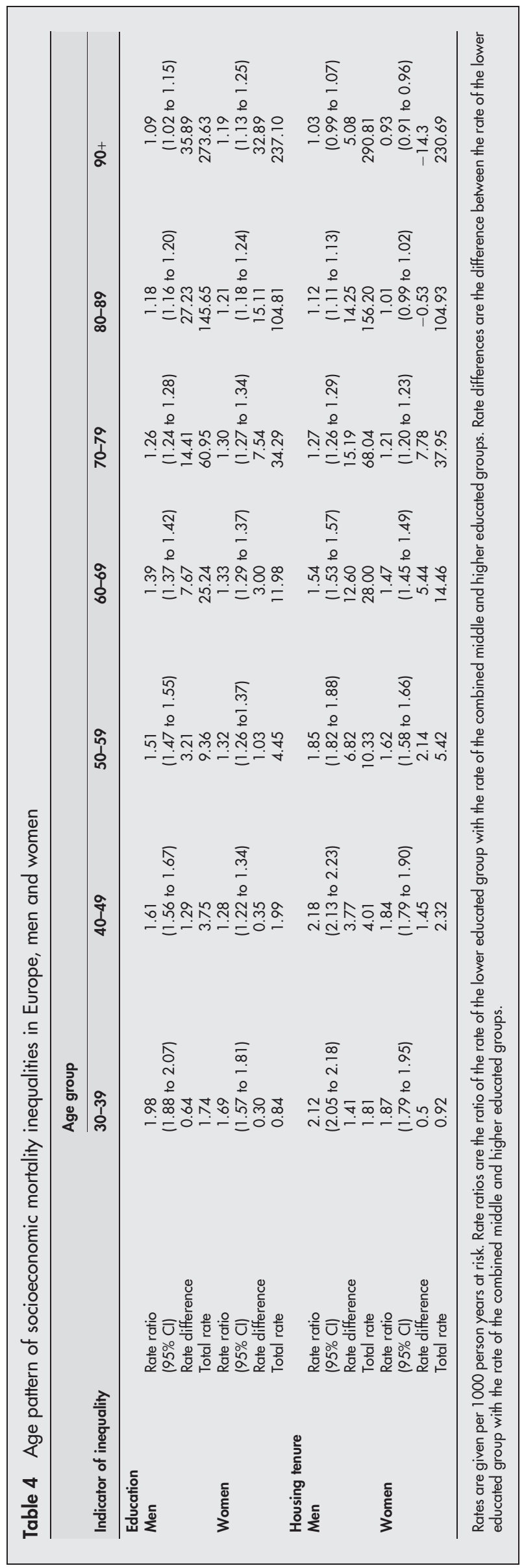

Rates are given per 1000 person years at risk. Rate ratios are the ratio of the rate of the lower educated group with the rate of the combined middle and higher educated groups. Rate differences are the difference between the rate of the lower educated group with the rate of the combined middle and higher educated groups. Relative and absolute mortality inequalities for the separate populations are shown in tables 5 and 6 .

Table 5 gives educational inequalities. The populations are listed geographically from north to south. In this table, the results for each population are given for the middle aged (ages 50-59) and elderly (ages 60-69, 70-79 and 80-89). Exceptions are Denmark and France for which the oldest age groups are 60-69 and 70-79 respectively. Among men, the relative inequalities (rate ratios) were lower among the elderly than among the middle aged in all populations, with the exception of England and Wales, where the largest inequalities were observed at ages 60-69. A gradual decrease of relative educational inequalities among women in the older groups was only found for Finland. There was still a relation between socioeconomic status and mortality at older ages. Only in England and Wales (among the oldest women) could relative inequalities not be illustrated with statistical significance. Absolute differences were consistently higher among the elderly population.

Differences between countries in the relative educational mortality inequalities are shown in the figures 3 and 4 . Variations in the extent of decrease of relative inequalities were found between populations. The decrease with age was large in Norway (men and women) and Austria (men). Smaller declines among women were also observed in Finland, England and Wales, and Barcelona and Madrid. In other populations the RIIs were similar or somewhat larger in the older age group.

Table 6 shows inequalities relating to housing tenure. Relative inequalities were consistently smaller among the oldest ages for all populations and both sexes. Among women these were statistically significant in Finland and Denmark only. The extent to which the inequalities declined differed between the populations. The peak in absolute differences was found in many populations at ages $70-79$, rather than 80-89, which was in agreement with the finding for the pooled European population that absolute differences in mortality related to housing tenure declined at the oldest ages.

\section{DISCUSSION}

This paper illustrated that not only absolute, but also relative socioeconomic inequalities in mortality among the elderly population persisted into old age and were considerable. Moreover we found that whereas relative socioeconomic mortality inequalities generally decreased with age, absolute inequalities increased with age. Finally, we observed that the age pattern of relative inequalities differed between populations among women. A decrease in relative inequalities by education with rising age among women was not evident in many populations.

Some limitations of the study must be discussed. Because of differences in the organisation of national educational systems, we collapsed those into a broad general classification, consisting of three levels, with most of the population falling into the lowest category. We checked what influence the use of this broad classification had on the results. Using a more refined classification that was available for some of the populations we found that a further division of the levels of education resulted in slightly larger relative and absolute inequalities, but that the age patterns did not change.

The follow up periods differed somewhat in length between studies. The studies for Austria and Madrid cover one and two years respectively, while other countries cover a period of four to five years. As a result the Austria and Madrid studies refer to a slightly younger population, which 


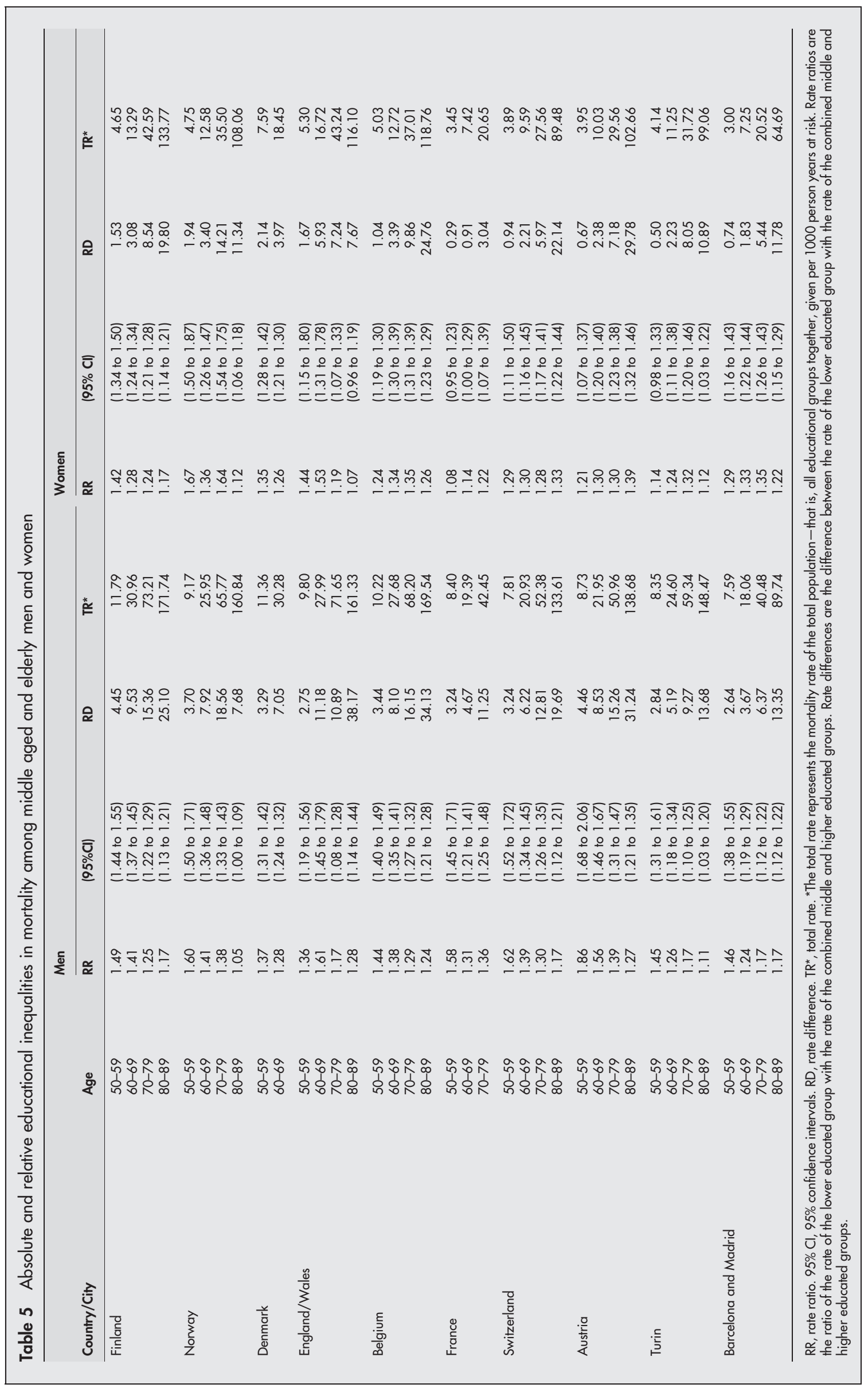




\begin{tabular}{|c|c|c|c|c|c|c|c|}
\hline \multirow[b]{2}{*}{ Country/Region } & \multirow[b]{2}{*}{ Age } & \multicolumn{3}{|l|}{ Men } & \multicolumn{3}{|c|}{ Women } \\
\hline & & RR & $(95 \% \mathrm{Cl})$ & RD & RR & $(95 \% \mathrm{Cl})$ & RD \\
\hline Finland & $\begin{array}{l}50-59 \\
60-69 \\
70-79 \\
80-89\end{array}$ & $\begin{array}{l}2.18 \\
1.90 \\
1.44 \\
1.20\end{array}$ & $\begin{array}{l}(2.09 \text { to } 2.26) \\
(1.84 \text { to } 1.95) \\
(1.40 \text { to } 1.48) \\
(1.16 \text { to } 1.25)\end{array}$ & $\begin{array}{l}11.49 \\
23.96 \\
30.19 \\
28.96\end{array}$ & $\begin{array}{l}1.82 \\
1.73 \\
1.32 \\
1.05\end{array}$ & $\begin{array}{l}(1.71 \text { to } 1.94) \\
(1.67 \text { to } 1.79) \\
(1.29 \text { to } 1.35) \\
(1.02 \text { to } 1.07)\end{array}$ & $\begin{array}{r}3.34 \\
8.50 \\
12.53 \\
4.70\end{array}$ \\
\hline Norway & $\begin{array}{l}50-59 \\
60-69 \\
70-79 \\
80-89\end{array}$ & $\begin{array}{l}1.65 \\
1.44 \\
1.16 \\
1.06\end{array}$ & $\begin{array}{l}(1.56 \text { to } 1.74) \\
(1.39 \text { to } 1.49) \\
(1.13 \text { to } 1.19) \\
(1.03 \text { to } 1.09)\end{array}$ & $\begin{array}{r}5.42 \\
11.10 \\
10.87 \\
6.75\end{array}$ & $\begin{array}{l}1.13 \\
1.36 \\
1.15 \\
1.01\end{array}$ & $\begin{array}{l}(1.03 \text { to } 1.23) \\
(1.30 \text { to } 1.42) \\
(1.12 \text { to } 1.18) \\
(0.99 \text { to } 1.03)\end{array}$ & $\begin{array}{l}0.60 \\
4.32 \\
5.46 \\
1.23\end{array}$ \\
\hline Denmark & $\begin{array}{l}50-59 \\
60-69 \\
70-79 \\
80-89\end{array}$ & $\begin{array}{l}2.15 \\
1.64 \\
1.36 \\
1.21\end{array}$ & $\begin{array}{l}(2.08 \text { to } 2.22) \\
(1.60 \text { to } 1.67) \\
(1.34 \text { to } 1.39) \\
(1.18 \text { to } 1.24)\end{array}$ & $\begin{array}{l}10.12 \\
15.96 \\
22.35 \\
27.97\end{array}$ & $\begin{array}{l}1.72 \\
1.47 \\
1.33 \\
1.13\end{array}$ & $\begin{array}{l}(1.66 \text { to } 1.79) \\
(1.43 \text { to } 1.51) \\
(1.30 \text { to } 1.36) \\
(1.10 \text { to } 1.15)\end{array}$ & $\begin{array}{r}4.49 \\
7.17 \\
11.44 \\
11.50\end{array}$ \\
\hline England/Wales & $\begin{array}{l}50-59 \\
60-69 \\
70-79 \\
80-89\end{array}$ & $\begin{array}{l}2.02 \\
1.65 \\
1.29 \\
1.17\end{array}$ & $\begin{array}{l}(1.80 \text { to } 2.27) \\
(1.53 \text { to } 1.77) \\
(1.21 \text { to } 1.37) \\
(1.08 \text { to } 1.27)\end{array}$ & $\begin{array}{r}8.07 \\
14.81 \\
18.51 \\
20.01\end{array}$ & $\begin{array}{l}1.93 \\
1.58 \\
1.36 \\
1.01\end{array}$ & $\begin{array}{l}(1.66 \text { to } 2.26) \\
(1.46 \text { to } 1.72) \\
(1.28 \text { to } 1.45) \\
(0.94 \text { to } 1.07)\end{array}$ & $\begin{array}{r}4.06 \\
8.20 \\
13.54 \\
0.38\end{array}$ \\
\hline Belgium & $\begin{array}{l}50-59 \\
60-69 \\
70-79 \\
80-89\end{array}$ & $\begin{array}{l}1.65 \\
1.44 \\
1.22 \\
1.08\end{array}$ & $\begin{array}{l}(1.61 \text { to } 1.70) \\
(1.41 \text { to } 1.46) \\
(1.20 \text { to } 1.24) \\
(1.05 \text { to } 1.10)\end{array}$ & $\begin{array}{r}5.68 \\
10.78 \\
14.40 \\
11.19\end{array}$ & $\begin{array}{l}1.60 \\
1.43 \\
1.12 \\
0.92\end{array}$ & $\begin{array}{l}(1.54 \text { to } 1.66) \\
(1.40 \text { to } 1.47) \\
(1.10 \text { to } 1.14) \\
(0.91 \text { to } 0.94)\end{array}$ & $\begin{array}{r}2.58 \\
4.83 \\
4.40 \\
-8.53\end{array}$ \\
\hline France & $\begin{array}{l}50-59 \\
60-69 \\
70-79\end{array}$ & $\begin{array}{l}1.34 \\
1.27 \\
1.12\end{array}$ & $\begin{array}{l}(1.27 \text { to } 1.42) \\
(1.20 \text { to } 1.34) \\
(1.05 \text { to } 1.19)\end{array}$ & $\begin{array}{l}2.49 \\
4.69 \\
4.88\end{array}$ & $\begin{array}{l}1.20 \\
1.25 \\
1.09\end{array}$ & $\begin{array}{l}(1.09 \text { to } 1.32) \\
(1.14 \text { to } 1.37) \\
(0.99 \text { to } 1.19)\end{array}$ & $\begin{array}{l}0.63 \\
1.68 \\
1.70\end{array}$ \\
\hline Turin & $\begin{array}{l}50-59 \\
60-69 \\
70-79 \\
80-89\end{array}$ & $\begin{array}{l}1.38 \\
1.37 \\
1.17 \\
1.06\end{array}$ & $\begin{array}{l}(1.27 \text { to } 1.49) \\
(1.29 \text { to } 1.44) \\
(1.11 \text { to } 1.23) \\
(1.00 \text { to } 1.13)\end{array}$ & $\begin{array}{l}2.73 \\
7.95 \\
9.56 \\
6.86\end{array}$ & $\begin{array}{l}1.31 \\
1.33 \\
1.14 \\
1.01\end{array}$ & $\begin{array}{l}(1.17 \text { to } 1.46) \\
(1.24 \text { to } 1.43) \\
(1.08 \text { to } 1.20) \\
(0.96 \text { to } 1.06)\end{array}$ & $\begin{array}{l}1.12 \\
3.29 \\
4.64 \\
0.22\end{array}$ \\
\hline
\end{tabular}

Abbreviations as for table 5. Rate ratios are the ratio of the rate of the lower educated group with the rate of the combined middle and higher educated groups. Rate differences are the difference between the rate of the lower educated group with the rate of the combined middle and higher educated groups.

may have resulted in a small overestimate of relative mortality inequalities in these populations.

Furthermore, mortality rates may have changed during the follow up periods because of, for instance, modifications in the organisation of healthcare programmes. However, we do not expect that this has influenced the results to a great extent, because the follow up periods cover about five years and it is not likely that mortality rates have changed much in such a short time frame.
The results for housing tenure are probably influenced by the exclusion of institutionalised populations. One hypothesis is that the elderly population who still rent a house are a selection of healthy people, because elderly tenants move more easily to institutions when they are faced with problems to live on their own. Research from England and Wales has shown that tenants have higher institutionalisation rates than owner occupiers. ${ }^{25}$ If tenants elsewhere also have a higher risk of becoming institutionalised when ill, this may

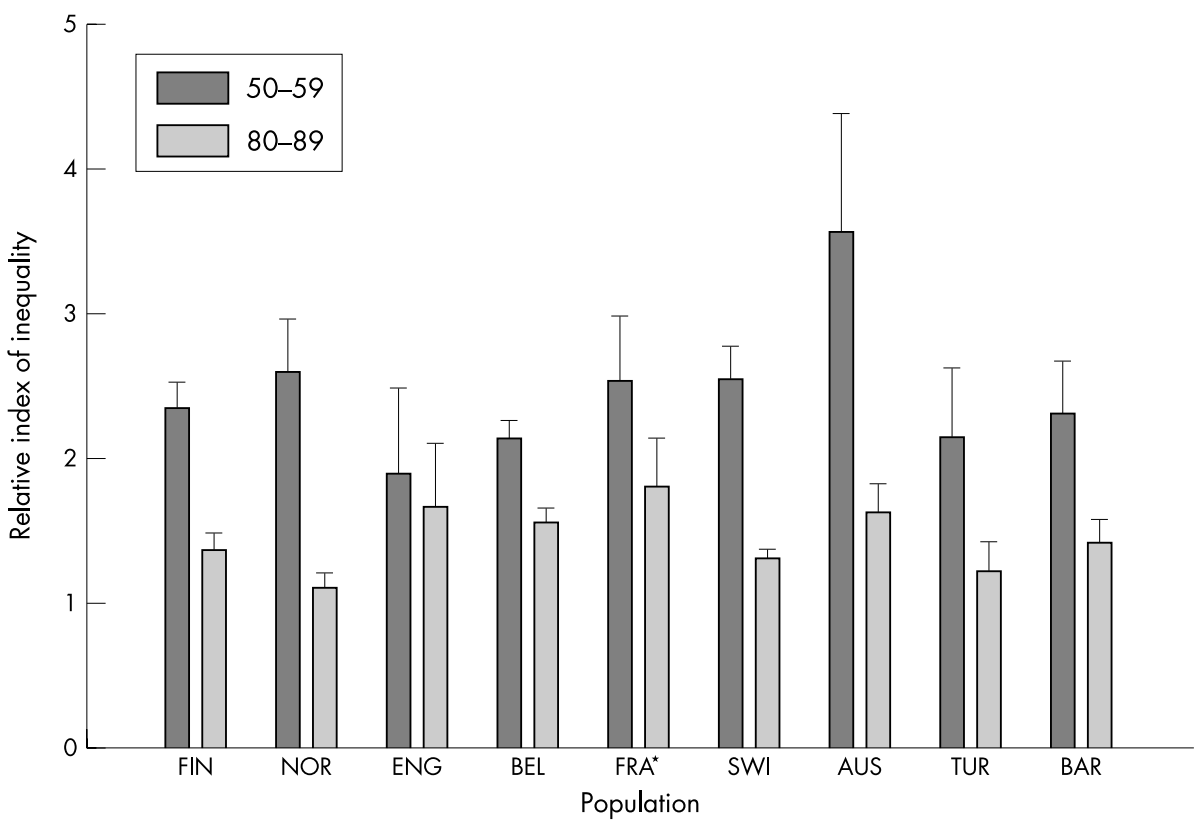

Figure 3 Size of educational inequalities in mortality for middle aged (50-59 years) and elderly (80-89) men. ${ }^{*}$ The oldest age group for France is 70-79. ENG, England and Wales. BAR, Barcelona and Madrid. The relative index of inequality is a regression based index that contrasts the rate of mortality that is predicted for the lower end of the educational hierarchy with the rate of mortality at the higher end of the hierarchy into a ratio. 


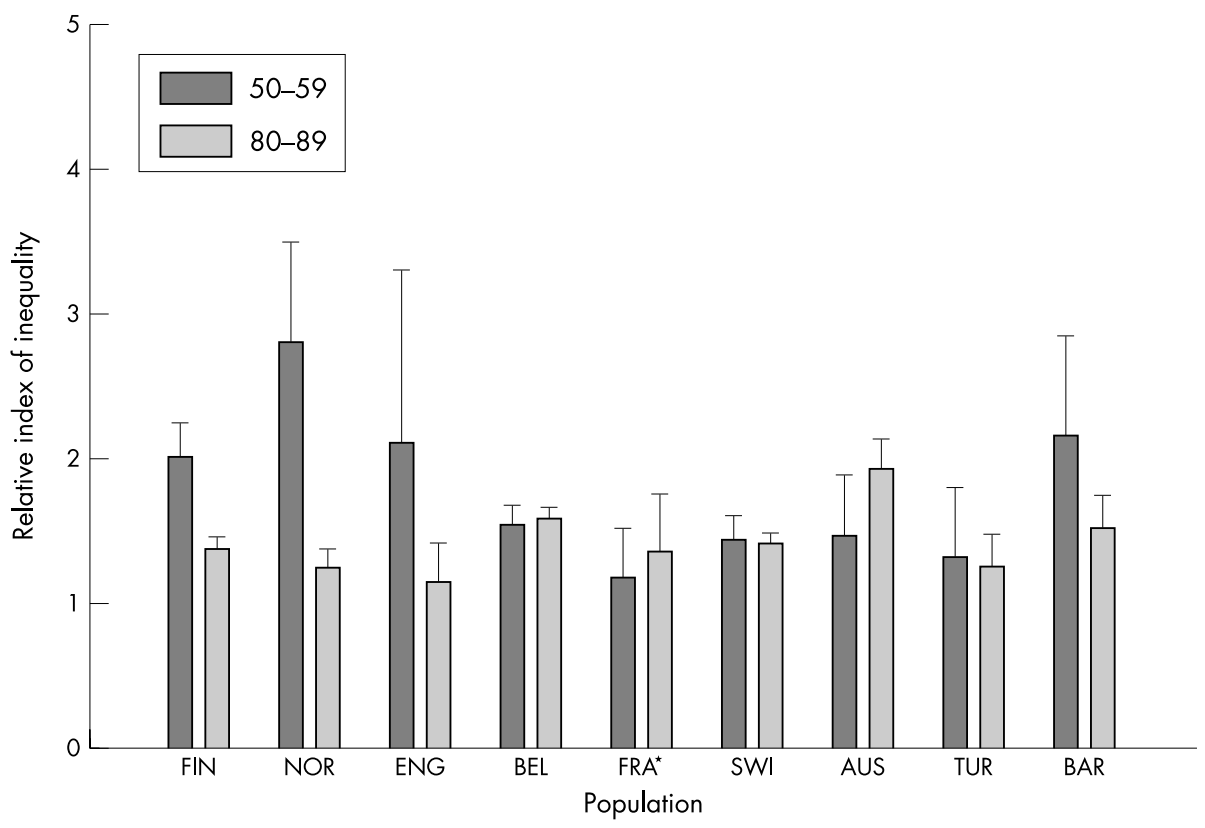

Figure 4 Size of educational inequalities in mortality for middle aged (50-59 years) and elderly (80-89) women. ${ }^{*}$ The oldest age group for France is 70-79. ENG, England and Wales. BAR, Barcelona and Madrid. The relative index of inequality is a regression based index that contrasts the rate of mortality that is predicted for the lower end of the educational hierarchy with the rate of mortality at the higher end of the hierarchy into a ratio. explain the attenuation of mortality differences by housing tenure at $80+$. The finding that inequalities attenuated more among women is in line with this explanation, as women are more likely to be institutionalised when disabled than men are. However, this is not likely to be the only explanation for the attenuation of the inequalities. In Norway, where the percentage of institutionalised is very low a large attenuation was observed.

Irrespective of the problem of institutionalisation mentioned above, housing tenure still acts as a conceptually complementary measure of socioeconomic status to education. Conveniently, it is an indicator that is available in many countries. Housing tenure was strongly related to mortality among the middle aged and among the early old age groups. We found that inequalities according to housing tenure were smaller as compared with educational inequalities only in the two oldest age groups. It seems that housing tenure is a useful indicator for both middle aged and elderly populations, except the oldest old. Future research could address a "four corners" approach to socioeconomic inequalities in mortality. Education and housing tenure may relate to different causal pathways and combining the two measures into one indicator may provide evidence of the relative importance of both pathways, as well as their combined effect.

\section{Key points}

- Absolute differences in mortality are substantial among the elderly populations in Europe.

- Relative socioeconomic inequalities in mortality are as large among the elderly as among the middle aged in some populations.

- Inequalities in mortality related to education and to housing tenure show varying patterns, suggesting that these determinants relate to different causal pathways.

- The high excess mortality among the elderly population of lower socioeconomic status constitutes an important public health problem. Active measures should be taken to reduce socioeconomic inequalities in mortality among the elderly population.
Our results are comparable with the results of previous studies. Although a few studies did not report socioeconomic inequalities among the elderly population, ${ }^{26-28}$ these were mostly epidemiological studies with small sample sizes. ${ }^{9}$ Studies with larger samples did find that inequalities in health persist into old age, including studies that report on inequalities related to other socioeconomic indicators than education and housing tenure, and studies based outside Europe. ${ }^{5-13}$ An important contribution of the results of this overview is the finding that relative inequalities among the elderly population were not consistently smaller than among younger age groups.

Furthermore, our study showed that absolute inequality measures reveal important information which relative measures alone cannot. We found that the absolute numbers of excess deaths among the lower socioeconomic groups were considerable at old age. Therefore it cannot be concluded that inequalities among elderly populations are of lesser importance than at middle age.

This study showed that the age pattern of inequalities in mortality differed between countries. These findings raise the question as to why relative inequalities in mortality decreased with age in some countries, while in other countries they remained about stable, or increased, especially among women. One explanation is that a decrease is more unlikely among women in some populations because relative inequalities among the younger women are not large to begin with. In fact, those populations that do show a decrease are those in which relative inequalities among younger women are almost as large as among men (Finland, Norway, and England and Wales).

As the results of this study are related to different cohorts, they can hide different stories. An apparent decline among older generations could hide a surge in inequality among younger cohorts (for example women in Nordic countries). One factor possibly involved in this is smoking. Social inequalities in smoking vary strongly by age group, with larger inequalities observed among younger than among older generations. ${ }^{29}$ This age dependency of inequalities in smoking may have influenced the age dependency of inequalities in mortality in many European populations, especially among male generations, which have had historically much higher lifetime exposure to smoking. International overviews have shown that strong age gradients in smoking inequalities, with smaller or even reverse 
gradients for the oldest cohorts, have persisted until the 1980s in most southern European populations. ${ }^{29}{ }^{30}$ In northern Europe in contrast, smoking has been more important in generating socioeconomic inequalities among men. This may explain the somewhat more pronounced age pattern among men in northern European populations.

Other risk factors for mortality should be considered as well. For example, alcohol misuse has been identified as an important cause of death among middle aged men in northern Europe. A Finnish study showed that alcohol misuse contributed substantially to the large inequalities in mortality among middle aged men, but much less so among older men. ${ }^{31}$ Thus, the relatively strong age gradient in relative inequalities in mortality in Finland is likely to be attributable in part to alcohol related mortality. Even though alcohol related mortality may have contributed as well to inequalities in mortality in more southern countries, these effects may have been spread more evenly over different age groups. Important is to note that, in contrast with the situation in southern countries, fatal alcohol misuse in northern Europe mainly takes the form of binge drinking leading to increased injuries and other actor causes of death that affect middle aged men in particular. ${ }^{32}$

Even though these explanations are tentative and require further exploration in future research, they serve to illustrate that many factors influence the age pattern of inequalities in mortality. Given these multiple influences, it should be no surprise that this age pattern strongly varies between countries and between men and women.

This study provided evidence for persisting socioeconomic inequalities in mortality among elderly populations in Europe. The large numbers of excess deaths that occur among the lower socioeconomic groups are an important public health problem. Even when relative inequalities in future elderly European populations will not increase but remain as we observed, the absolute numbers of excess deaths will increase, as a result of the aging of the population within these countries. There is as yet no indication that socioeconomic inequalities in mortality among the elderly population will become less. However, the variations in mortality inequalities that are observed between countries suggest that reducing inequalities is an achievable goal for elderly populations as well.

\section{ACKNOWLEDGEMENTS}

Swiss data are from the Swiss Federal Office of Statistics. The authors would like to thank Jetty Dalstra for her comments on previous versions of this paper.

\footnotetext{
Authors' affiliations

M Huisman, A E Kunst, J P Mackenbach, Department of Public Health, Erasmus Medical Center, Rotterdam, Netherlands

O Andersen, Research and Methodology, Statistics Denmark, Copenhagen, Denmark

M Bopp, Institute for Social and Preventive Medicine, University of Zurich, Switzerland

J-K Borgan, Division for Health Statistics, Statistics Norway, Oslo, Norway

C Borrell, Municipal Health Service, Barcelona, Spain

G Costa, T Spadea, Department of Public Health and Microbiology, University of Turin, Italy

P Deboosere, S Gadeyne, Interface Demography, Free University

Brussels, Belgium

G Desplanques, INED, Paris, France

A Donkin, Health and Care Division, Office for National Statistics, London, UK

C Minder, Institute for Social and Preventive Medicine, University of Bern, Switzerland

E Regidor, Department of Preventive Medicine and Public Health, University of Madrid, Spain

T Valkonen, Department of Sociology, University of Helsinki, Finland
}

Funding: This study is based on a grant (contract QLK6-CT-199902161) of the Fifth Framework Programme on "Quality of Life and Management of Living Resources" of the European Union. The construction of the Swiss National Cohort has been supported by the Swiss National Science Foundation, grants number 32-5884.98 and 32-63625.00.

Conflicts of interest: none declared.

\section{REFERENCES}

1 Fox AJ, ed. Health inequalities in European countries. Aldershot: Gower, 1989.

2 Illsley R, Svensson P-G, eds. Social inequalities in health. Soc Sci Med 1990:31:223-40.

3 Kunst AE, Mackenbach JP. The size of mortality differences associated with educational level in nine industrialized countries. Am J Public Health 1994;84:932-7.

4 Mackenbach JP, Kunst AE, Cavelaars AE, et al. Socioeconomic inequalities in morbidity and mortality in western Europe. Lancet 1997;349:1655-9.

5 Victor CR. Inequalities in health in later life. Age Ageing 1989;18:387-91

6 Goldblatt PO. Longitudinal study. Mortality and social organisation 19711981. London: Office of Population Censuses and Surveys, 1990.

7 Olausson PO. Mortality among the elderly in Sweden by social class. Soc Sci Med 1991;32:437-40.

8 Valkonen T. Problems in the measurement and international comparisons of socio-economic differences in mortality. Soc Sci Med 1993;36:409-18.

9 Martelin T, Koskinen S, Valkonen T. Sociodemographic mortality differences among the oldest old in Finland. J Gerontol B Psychol Sci Soc Sci 1998;53:S83-90

10 Martelin T. Mortality by indicators of socioeconomic status among the Finnish elderly. Soc Sci Med 1994;38:1257-78.

11 Bassuk SS, Berkman LF, Amick BC III. Socioeconomic status and mortality among the elderly: findings from four US communities. Am J Epidemiol 2002; 155:520-33.

12 Broese van Groenou MI, Deeg DJH. Sociaal-economische gezondheidsverschillen bij ouderen [Socio-economic differences in health among the elderly]. Tijdschrift voor gezondheidswetenschappen 2000:78:294-302.

13 Van Rossum CTM, Van de Mheen H, Mackenbach JP, et al. Socioeconomic status and mortality in Dutch elderly people. Eur J Public Health 2000;10:255-61

14 Marmot MG, Shipley MJ. Do socioeconomic differences in mortality persist after retirement? 25 Year follow up of civil servants from the first Whitehall study. BMJ 1996;313:1170-80.

15 Martikainen P, Makela P, Koskinen S, et al. Income differences in mortality: a register-based follow-up study of three million men and women. Int J Epidemiol 2001;30:1397-405.

16 Beckett $M$. Converging health inequalities in later life-an artefact of mortality selection. J Health Soc Behav 2000;41:106-19.

17 Fox AJ, Goldblatt PO. Socio-demographic mortality differentials from the OPCS longitudinal study 1971-75 (series LS no. 1). London: HMSO, 1982.

18 Fox AJ, Goldblatt PO, Jones DR. Social class mortality differentials: artefact, selection or life circumstances? J Epidemiol Community Health 1985;39:1-18.

19 Arber S, Ginn J. Gender and inequalities in health in later life. Soc Sci Med 1993:36:33-46.

20 Unesco. International standard classification of education 1997. (http:// www.unesco.org/education/information/nfsuriesco/doc/isced_1997.htm).

21 Eurostat. Demographic statistics 1997. Luxembourg: Office for Official Publications of the European Communities, 1997.

22 Mackenbach JP, Kunst AE. Measuring the magnitude of socio-economic inequalities in health: an overview of available measures illustrated with two examples from Europe. Soc Sci Med 1997;44:757-71.

23 SAS. SAS user's guide: statistics, version 6 edition. Cary, NC: SAS Institute, 1989.

24 Borrell C, Regidor E, Arias LC, et al. Inequalities in mortality according to educational level in two large Southern European cities. Int J Epidemiol 1999:28:58-63.

25 Breeze E, Sloggett A, Fletcher A. Socioeconomic and demographic predictors of mortality and institutional residence among middle aged and older people: results from the longitudinal study. J Epidemiol Community Health 1999:53:765-74.

26 Kaplan GA, Seeman TE, Cohen RD, et al. Mortality among the elderly in the Alameda County study: behavioral and demographic risk factors. Am J Public Health 1987;77:307-12.

27 Jagger C, Clarke M. Mortality risks in the elderly: five-year follow-up of a total population. Int J Epidemiol 1988;17:111-14.

28 Palmore EB. Predictors of the longevity difference: a 25 -year follow-up. Gerontologist 1982;22:513-18.

29 Cavelaars AEJM, Kunst AE, Geurts JJM, et al. Educational differences in smoking: international comparison. BMJ 2000;320:1102-7.

30 Graham H. Smoking prevalence among women in the European Community 1950-1990. Soc Sci Med 1996;43:243-54.

31 Makela P, Valkonen T, Martelin T. Contribution of deaths related to alcohol use to socioeconomic variation in mortality: register based follow up study. BMJ 1997;315:211-16.

32 Hemström Ö. Alcohol-related deaths contribute to socioeconomic differentials in mortality in Sweden. Eur J Public Health 2002;12:254-62. 